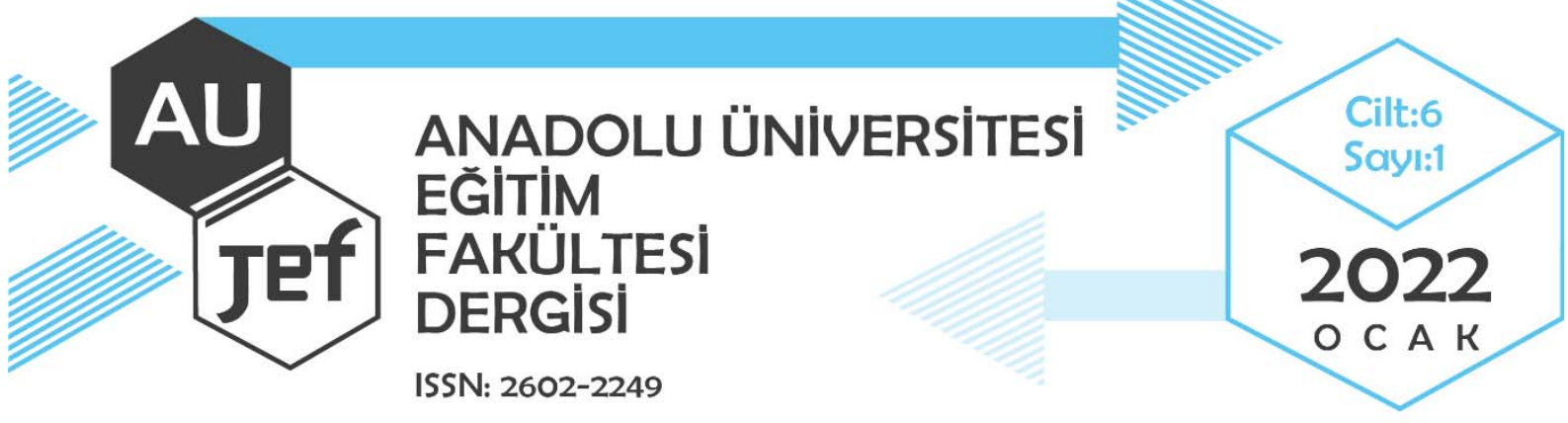

\title{
Benliğin Neoliberal Öyküsü ve Psikolojik Danışma
}

\section{The Neoliberal Story of the Self and Counseling}

\author{
Mehmet SARIÇALI ${ }^{1}$
}

Makale Türü: Derleme

Başvuru Tarihi: 12.07 .2021

Kabul Tarihi: 18.01 .2022

Atıf İçin: Sarıçalı, M. (2022). Benliğin neoliberal öyküsü ve psikolojik danışma. Anadolu Üniversitesi Eğitim Fakültesi Dergisi (AUJEF), 6(1), 31-38.

ÖZ: Psikolojide neyin bilgi değeri taşıdığı ve ne tür konuların araştırılabileceği, içinde bulunulan dönemin yansımalarından etkilenebilmektedir. Neoliberalizmin sosyopolitik düzlemi yeni bir psişe anlatısı ortaya koymuşstur. Bu psişe anlatımı doğrultusunda, neoliberal sistem benliğe yönelik bilgiyi ve öyküyü yeniden yapılandırmıştır. Bu çalışmada, neoliberal politikaların psikoloji ve daha özelde de psikolojik danışma alanında yansımaları tartışılmıştır. İlgili yazın incelendiğinde mikro tahakküm alanı olarak birey/ özne, mikro tahakküm biçimi olarak içselleştirilmiş disiplin ve psikolojinin çeşitli yöntemlerle piyasalaşması ya da bireyliğin piyasalaş̧tırılması temaları üzerinde durulmuştur. Ayrıca neoliberal sistemde benliğin yeniden yapılandırılma biçimi incelenmiş, İçsel disipline etme sürecinde benliğe ve duygulara değinilmiştir. Psikolojik danışma alanında bireyin özerkliği ve pozitif gelişiminin sosyal adalet paradigmasıyla bütünleştirilmesinin gereğine vurgu yapılmıştır. Neoliberalizm bağlamındaki eleştirel yazın çerçevesinde oluşturulan bu temaların psikolojik danı̧̧ma alanına olası yansımaları ele alınmış, sosyal adalet paradigması çerçevesinde psikolojik danışma alanına yönelik önerilere dikkat çekilmiştir. Güçlülük temelli müdahalelerde, iyi oluşun yanında benliğe yönelik neoliberal baskıdan özgürleşme vurgusu yapılmıştır.

Anahtar sözcükler: Benlik, Duygular, Neoliberalizm, Psikolojik danışma

ABSTRACT: Epistemology and methodology in psychological research may be affected by the reflections of the current period. The sociopolitical plane of neoliberalism has revealed a new psychic narrative. In line with this narrative, the neoliberal system has reconfigured the knowledge and discourse about the self. In this study, the reflections of neoliberal policies on the field of psychology and more specifically on counseling are discussed. When the literature is examined, the themes of the subject as the practice of micro governmentality, the internalized discipline as the form of micro governmentality, and the marketing of psychology as well as new forms of individuality through various methods are stressed. In addition, the way of reconfigurations of the self in the neoliberal system, and the cultivation of emotions and internal discipline in line with micro-governmentality practices were discussed. In counseling, the necessity of integrating the individual agency, positivity, strengthbased intervention with the social justice and advocacy paradigm is highlighted. Furthermore, in a therapeutic relationship, the emphasis is placed on the motivation of liberating the self from neoliberal pressure as well as improving well-being in strength-based interventions.

Keywords: Self, Emotions, Neoliberalism, Psychological Counseling

\footnotetext{
${ }^{1}$ Dr. Öğr. Üyesi, Nevşehir Hacı Bektaş Veli Üniversitesi, mehmetsaricali@nevsehir.edu.tr, ORCID: 0000-00032368-8146
} 


\section{GíRiș}

Neoliberalizm, kapitalizmin yoğunlaşmış ve genişlemiş biçimini içeren sosyo-politik ve ekonomik sistemdir (Ratner, 2019). Bu sistemde tahakküm, rekabet temel değeri etrafında, atomize edilmiş bireysel alana doğru radikal bir biçimde yönelmektedir (Steger ve Roy, 2010). Neoliberal kurumlar, politikalar, değerler psişik alanda duygusal bir baskıya dönüşmektedir (Herrawi, Logan, Cheng ve Cosgrove, 2021). $\mathrm{Bu}$ değerler ve dönüşüm çerçevesinde de yeni bir özne/ öznellik şekillenmektedir. Neoliberalizm ile kişilik, benlik, kimlik, psikolojik yaşantı ve etik sorumluluk gibi kavramlar yeniden yapılandırılmıştır (Sugarman, 2015). Klasik kapitalizmin ötesinde, kendi kendini disipline edecek etik normlara sahip "özne" neoliberalizmde öne çıkmaktadır. Neoliberalizmin klasik kapitalizmden farklılaştığı nokta, üretilen normların birey tarafından içselleştirilmesi ve böylelikle bireyin kendi kendisini disipline etmesidir (LaMarre, Smoliak, Cool, Kinavey ve Hardt, 2019). İçsel disipline etme sürecinde benlik ve duygular nesneleşebilmektedir. Bir başka ifadeyle, duygular ve benliğin yapılandırılması bireyliğin neoliberal dönüşümünde kritik noktadır.

Kendi kendini disipline edebilen bir öznenin ortaya çıkarılmasıyla ekonomik ve politik yapılar iç içe girmekte ve akışkanlaşmaktadır (Teo, 2017). Mikro alanda özerk olarak seçim yapabilen birey yanılsaması kimi zaman kurumsallaşmış eşitsizlikler ile depresyon gibi bireysel alandaki sonuçlar arasındaki nedensel bağıntıyı muğlaklaştırabilmektedir (Cosgrove ve Vaswani, 2020). Dolayısıyla bireyde, bir sorun varsa bunun kaynağının bireyin kendisinin firsatları yeterince değerlendiremediği algısı gelişmektedir. Sistemik engellemeler ve kısıtlamalar bu şekilde fark edilmesi güç örtük bir biçime bürünmektedir. Mikro anlamda öznellik, beden, benlik ve duygular bir tahakküm alanına dönüşmektedir. Benliğin kavramsallaştırılması ve yapılandırılması içinde bulunulan dönemin ekonomik ve politik koşulları doğrultusunda gerçekleşmektedir (Cushman, 1990). Neoliberalizm doğrultusunda oluşturulan yeni benlik ve psişe anlatısı psikolojide bilgi üretimini ve bilginin uygulanmasını örtük ya da açık şekilde etkileyebilmektedir (Adams, Estrada-Villalta, Sullivan ve Markus, 2019). Benliğin ve kimliğin oluşumu dönüşen yeni güç ilişkileri doğrultusunda yeniden çerçevelenmiştir. Somut iktidar biçimi neoliberalizmle birlikte, makro alanın yanında mikro alanda da kendisini oluşturmakta ve yeniden üretmektedir. Neoliberal tahakküm yöntemleri, hem mikro alanda kişinin kendini disipline etmesi hem de makro alanda otoritelerin bireyi disipline etmesi şeklinde oluşmaktadır (Carr ve Batlle, 2015). Neoliberal dönemde kişi, ebeveynler, öğretmenler, işverenler, uzmanlar gibi kılcal mikro iktidar örüntüleri aracılığıyla makro iktidara eklemlenmektedir (Foucault, 2015). Mikro tahakküm yöntemleriyle pazar içerisinde merkezi otoriteye gerek duyulmaksızın bireyler kendi kendilerini yönetebilen "özgür" girişimcilere dönüştürülmüştür (Sugarman, 2015).

\subsection{Neoliberal Sistemde Biçimlendirilen, Akışkanlaştırılan Bir Nesne Olarak Benlik}

Neoliberalizm benliğe yönelik üç temel söylem üretmiştir. Bunlar normal benlik, gelişen benlik ve üretken benliktir (LaMarre ve diğ., 2019). Neoliberal sistemde benliğin bağlamından koparılması, akışkanlaştırılması söz konusudur. Benliğin kendi kendinin girişimcisi ve bir proje olarak geliştiricisi olması temel ön koşul olarak kabul edilmektedir (Adams ve di ğ., 2019). Kişi kendisini geliştirilmesi ve sürdürülmesi gereken bir dizi beceri ve donanımlara sahip bir yatırım nesnesi gibi görmektedir (Sugarman, 2015). Benlik kendi kendini terbiye eden ve bir proje olarak oluşturan bir "özne" olarak görülmektedir. Bir başka ifadeyle, modern benlik bir teknisyen ya da sanatçı gibi benliğini oluşturma sorumluluğunu taşımaktadır (McAdams, 1996). Bu durumda makro iktidar, mikro iktidar aracılığıyla görünmezleşmekte ve akışkanlaşmaktadır. Bunun sonucunda da neoliberal güç ilişkilerinin anlaşılması ve dönüştürülmesi bulanıklaşmaktadır. 
Benliğin neoliberalizm doğrultusunda kendi kendine tahakküm etmesinde önemli rol oynayan faktörlerden birisi normalleştirmedir. Normalleştirme tam anlamıyla istatistiksel olarak ortalamanın baştan çıkarıcıllı̆̆ ya da baskısı değildir. Benliğin tüketen bir "özne" olarak kendini oluşturması ve beslemesidir. Tarihsel süreç içerisinde farklı koşullarda benlik için farklı normatif idealler üretilmiştir. Victorian dönemde cinsel anlamda benliğin baskılanması norm iken neoliberal dönemde içi boşaltılan benlik, tüketme ve ün üzerinden yeniden biçimlendirilmektedir (Cushman, 1990). Cushman'a (1990) göre özellikle ikinci dünya savaşı sonrasında benlik bu parçalanma ve yabancılaşma çağında, içine düştüğü boşlukla ürünleri, politikacıları, romantik ilişkileri ve empatik psikolojik danışmanları daha çok tüketerek mücadele etmeye çalışmaktadır. Bu noktada bir özne olarak benliğin hem eşsiz olma hem de normlar tarafından şekillendirilmesi bir ikilem gibi gözükebilir. Ancak neoliberal normal içerisinde benlik bir yandan eşsiz bir özne olarak oluşturulurken bir diğer yandan kendisini makro tahakküm alanına eklemleyen bir bağlam içerisinde çözünmektedir. Bu arada kalmışlı̆̆ın sonucu yabancılaşma ve parçalanma olabilmektedir. Bu parçalanmışlığın çözümü ise içselleştirilmiş bir disiplin ile mikro tahakküm alanına eklemlenen benliktedir. $\mathrm{Bu}$ anlamda, psikoloji ve psikolojik danışma alanındaki bazı uygulamalar kurumsal ihtiyaçlar doğrultusunda bireyin kendini disipline etmesine aracılık edebilmektedir (Martínez-Guzmán ve Lara, 2019).

Neoliberal benlik hasta olduğunda ilaç almak, yoga ve egzersiz yapmak, daha çok eğitim almak gibi öz yönetim stratejileri geliştirmelidir (Brijnath ve Antoniades, 2016). Bu noktada benlik neoliberal olanakları doğru kullanmaya kendini hazırlamalıdır. Neoliberal sistem içerisinde ticarileşen günlük yaşantı pratikleri, şirketleşen hizmetler, temelsizleşen bireycilik, özelleşen kamusal alan temel değere dönüşmektedir (Carr ve Batlle, 2015). Dolayısıyla benlik bu değerlere eklemlenmek için öz yönetim becerileri geliştirerek makro tahakkümün etki alanına girmektedir. Ancak benliğin neoliberal normalleştirilmesi açık bir şekilde gelişmemektedir. Benliğin örtük normalleştirilmesi sürecinde belirsizlik önemli bir olgudur. Benlik kendini ün ve tüketim gibi normlar üzerinden tanımladığında normal ve normal olmayan ilişkisi belirsizleşmektedir. Normal ve normal olmayan belirsizliği klasik kapitalizmle kıyaslandığında neoliberal sistemi besleyen temel olguya dönüşmüştür (Bauman, 2017). Belirsizliğin neoliberalizmde odakta yer almasının bazı nedenleri vardır. Bu nedenlerden en çok dikkat çekeni, oluşturulan kültürel iklimde kişisel özerkliğin öne çıkmasından günlük yaşantıda eşitsizliklerin görünmez duruma getirilmesidir (Calder-Dawe ve Gavey, 2019). Bu şekilde rekabet temelli habitatta, rekabet koşullarına uygun şekilde agresif bir benmerkezcilik ve benliği biçimlendirme sorumluluğu oluşmaktadır (Ratner, 2019). Böylelikle yapısal kısıtlamalar ile bireyin özerkliği geçirgenleşmektedir. $\mathrm{Bu}$ belirsizliğin nedeni ve sonucu olarak duygular önemli rol oynamaktadır.

\subsection{Benliğin Neoliberal Dönüşümünde Duygular}

Neoliberal tahakkümün önemli yöntemlerinden birisi, bireyin kendi duygu ve düşüncelerini normatif başarı, üretkenlik ve kar elde etmek için işlemesini sağlamaktır (Carr ve Batlle, 2015). Örneğin depresyonun önemli belirleyicilerinden olan mükemmeliyetçilik algısı 1989-2016 yılları arasında doğrusal bir artış göstermiştir (Curran ve Hill, 2019). Birey yarışı kaybetmemek için kusursuz olmak durumunda hissetmektedir. Böylelikle "başarısızlık" durumunda sorun bireyin yeterince mükemmel olamamasındadır. Mükemmeliyetçi algının sonucunun da yetersizlik ve suçluluk gibi çökkün hissetmeyi tetikleyebilecek ikincil duyguları ortaya çıkarabileceği öne sürülebilir. Neoliberalizm kimi zaman örtük kimi zaman da açık olarak belirsizlik algısını artırmaktadır. Belirsizlik ise kaygının temel nedenlerindendir (Barlow, 2000). Genel bir kaygı ve belirsizlik nedenselliğinin yanında neoliberalizm ontolojik bir belirsizlik oluşturmaktadır. Ontolojik belirsizliğin temel nedeni bireyin bazı durumlarda 
farkındalığının dışında gelişebilen, çalışma ve mesleki yaşantısındaki belirsizliktir. İşini kaybetme şeklinde örtük olarak beliren güvensizlik ve belirsizlikle oluşan baskı sonucunda varoluşsal kaygı oluşmaktadır (Neilson, 2015). Birey "kazanımlarını" kaybetme ve aynı zamanda "sınırsız olanakları" kaçırma kaygısını iç içe geçmiş bir şekilde hissedebilmektedir.

Günümüzde temel yaşamsal gereksinimlerinin karşılanmaması birey için bir endişe kaynağına dönüşmüştür. Neoliberal değerlerin baskın olmadığı dönemlerde meslek kişi için hem maddi anlamda hem de kimliksel anlamda bir güvenliğin garantisi anlamına gelebilmekteydi. Ancak neoliberal sistemin gelişmesi ile birlikte birey yaşamı boyunca köklü mesleki değişimler yapmak durumundadır. Yirminci yüzyılın sonlarına kadar meslek bir kimlik ve güvence olarak görülürken, günümüzde kariyer danışmanları kişilerin mesleki yaşantılarında 3-5 yılda bir meslek değiştirebileceklerine yönelik öngörüde bulunmakta ve bu doğrultuda kişileri hazırlayabilmektedir (Sugarman, 2015). Dolayısıyla güvenlik algısı yerini kaygıya bırakmıştır. Köklü mesleki değişimlerin oluşturduğu sınırsız "olanaklardan" yararlanamıyorsa bu tamamıyla bireyin "sorumluluğundadır." O nedenle güvensizlik ve kaygı ile baş etmek için birey kendinde risk alma becerileri, değişime açıklık gibi özellikleri geliştirmek durumunda hissetmektedir. Bu özelliklerin geliştirilmesindeki belirsizlik de kimi zaman ontolojik kaygıyı ontolojik suçluluğa dönüştürebilmektedir.

Kendi kendinin girişimcisi olan bireyin oluşturması gereken bir diğer duygu mutluluktur. Neoliberal sistemde mutluluk mesleki başarı ve ilişkiler için harcanabilmek üzere biriktirilen akışkan bir duygusal dövize dönüşmüştür (De La Fabián ve Stecher, 2018). Tüketim kültüründe tüketilen her bir ürün ya da hizmet sonucu ile mutluluk duygusu arasında kurulan bağlantı (Cabanas, 2016), mutluluğun sistem için harcanması gereken bir metaya dönüşmesini açıklamaktadır. Mutluluk, akışkanlığıyla yeni özneyi sadece neoliberal sisteme uyum sağlatmakla kalmaz sistemi yeniden üretmeye yarayan bir olguya dönüşür. Mutluluk için güzellik ve fit olma, moda önerileri; kendi kendine yardım kitapları ve telefon uygulamaları birçok öneri sağlamaktadır (Cabanas, 2016). Cabanas'a (2016), göre tüm bunlar duygusal olarak mutluluğun tamamıyla bireyin alanında olduğu görüşünü rasyonelize etmekte ve özgün benliğin tüketilmesine yol açmaktadır. Dolayısıyla mutluluk hem tüketilmesi beklenen hem de tüketime bireyi eklemleyen bir metaya dönüşebilmektedir.

Daha geniş bir açıdan bakıldığında, yirminci yüzyılın sonlarından başlayarak bireylerde pozitif olma baskısı oluşturulmuştur. Gülümse, neşeli ol, olumlu tarafından bak, şikâyet etme basitliğinde söylemlerle dolu kişisel gelişim endüstrisinin yaygınlığı pozitifliğin tiranlığg şeklinde betimlenmiştir (Held, 2002). Birey çökkün hissediyorsa, bu o kimsenin olayın olumlu tarafını görmemesindendir. O halde bireyin mutsuz olmasının önünde kendi dışında pek bir faktör yoktur şeklinde yaklaşımlarla mutluluk duygusu neoliberal kültürün tükettiği ve kendisini yeniden ürettiği önemli bir duyguya dönüşmektedir. Psikoloji alanındaki bazı yaklaşımlar da bu algıyı pekiştirebilmektedir. Örneğin pozitif psikolojide mutluluk ve başarı için bireysel kaynaklara odaklanılırken, başarısızlık durumundaki sosyo politik engeller göz ardı edilebilmektedir (Miller, 2008).

Mutluluk ve pozitif hissetme kaygıya benzer şekilde belirsizlikle iç içe girmektedir. Örneğin fit olma/olmama olgusu, sağlıklı ya da sağlıksız olma olgusundaki gibi daha belirgin çizgilerle ayrışmamaktadır (Bauman, 2017). O nedenle fit olmak gerçekleştirilebilecek bir hedef olmadığından bedenin nesneleşmesi ve mikro disiplin süreci işlemeye devam etmektedir. 


\section{SONUÇ}

$\mathrm{Bu}$ çalışmada benlik ve duyguların neoliberal dönüşümü ve kullanımı tartışılmıştır. Benliğin ve duyguların neoliberal dönüşümünde mikro tahakküm (Foucault, 2015) yöntemleri üzerinde durulmuştur. Neoliberalizmin örtük işleyişi ve psikolojik süreçler ilişkisine vurgu yapılmıştır.

Benliğin temel ikilemlerinden birisi aynı anda özne ve nesne olmaktır (May, 1980). Bu ikilem doğrutusunda güncel olarak benliğin özerk işlevselliğinin evrensel olarak geçerliği üzerinde durulmaktadır (Kagitcibasi, 2013). Kendi öyküsünü oluşturma yönüyle öznenin özerkliği öne çıkmaktadır. Bununla birlikte örneğin öz farkındalığın benlik için işlevselliği kadar çökkünlüğün de temeli olabileceği tartışması (Silvia ve O'Brien, 2004) önemlidir. Dolayısıyla benliğin pozitiflik çağında sınırsız olanakları kullanarak kendi öyküsünü oluşturmasını beklemek bir tür neoliberal baskıya dönüşebilmektedir. Özgür seçim yanılsaması örtük bir baskı oluşturabilmektedir (Schwartz, 2000). Bu tartışmalardan yola çıkarak psikolojik danışma alanında benlik üzerindeki neoliberal tahakkümün de göz önüne alınması gerekmektedir. Benliğin salt pozitif gelişimi odaklı bakış açısı beklenenin aksine olumsuz sonuç verebilmektedir. Güçlülük temelli müdahalelerin yanında haksavunuculuğu ve sosyal adalet temelli anlayışa gereksinim vardır.

Neoliberalizmle birlikte ortaya çıkan eşitsizliklerle mücadele, psikolojik danışma alanında çalışanlar için yönlendirici paradigmaya dönüşmeye başlamıştır. Örneğin birden fazla dezavantajlı durumun tekil olarak toplamlarından daha çok olumsuz sonuç verebileceğini kavramsallaştıran kesişimsellik paradigmasının psikolojik danışmanlıkla bütünleştirilmesi ve iç içe geçmiş yapısal sınırlıkların aşılmasında psikolojik danışmanın rolü üzerinde durulmuştur (Cole, 2009; Moradi ve Grzanka, 2017; Rosenthal, 2016). İçiçe girmiş yapısal baskılarla birlikte, bireyin içselleştirdiği örtük disiplin süreçlerinde de psikolojik danışmanın özgürleştirici işlevi önemlidir. Geleneksel olarak bakıldığında psikolojik danışmada bireyin güçlü yanlarının ortaya çıkarılması odaklı bir ilerleme vardır. $\mathrm{Bu}$ nedenle bireyin güçlü özelliklerinin ortaya çıkarılmasında pozitif psikoloji ve pozitif psikolojinin çalışma konularının psikolojik danışma ile örtüştüğü vurgulanmaktadır (Georges ve Tomlinson-Clarke, 2015; Magyar-Moe Owens ve Scheel, 2015; Vera ve Shin, 2006). Neoliberal bağlam düşünüldüğünde güçlülük temelli psikolojik danışma araştırma ve uygulamalarının öncesinde örtük sistemik baskılarla başa çıkma konusunda psikolojik danışmanlar yeterlik kazanmalıdır. Bu nedenle psikolojik danışma alanında, psikanalitik, bilişsel davranışçı, insanc1/ varoluşçu ve çok kültürlüğün sonrasında sosyal adalet paradigmasının yönlendirici güç olmasının gereği tartışılmaktadır (Ratts, 2009).

Psikolojik danışmanın güçlülük temelli müdahale anlayışı sosyal adalet paradigmasıyla örtüşmektedir (Prilleltensky, 2008). Aynı şekilde esenliğin yanında adaletin insancı psikoloji temelli yaklaşımlarda temel değer olmasının gereği üzerinde durulmuştur (Duff, Rubenstein ve Prilleltensky, 2016). Dolayısıyla salt "pozitif” kavramların geliştirilmesi eksik bir bakış açısıdır. Mutluluk, akış, farkındalık, öz yönetim gibi olguların danışanlarda gelişmesi ancak sosyal adalet temelli bir bakış açısıyla bütünleştirildiğinde bir anlam ifade etmektedir. Psikolojik danışmada sosyal adaletin temel paradigmaya dönüşmesine karşın, psikolojik danışma alanında bu konuda temel sınırlılıklar bulunmaktadır. Örneğin; sınıfsal farklılıklar temelli sosyal adalet çalışmalarının psikolojik danışmada eksikliğine dikkat çekilmiştir (Smith, 2008). Somut sınıfsal eşitsizliklerin yanında örtük olarak özne ve beden üzerinde tahakküm kuran neoliberal aygıtların çözümlenmesi de psikolojik danışmada sosyal adalet paradigmasının yerleşmesi bakımından önemlidir. Bu nedenle psikolojik danışman eğitiminde ve süpervizyonunda bu durumu içeren modellere yer verilmesi işlevsel gözükmektedir.

Etik Kurul İzin Bilgisi: Bu araştırma, etik kurul izni gerektirmemektedir. 


\section{KAYNAKLAR}

Adams, G., Estrada-Villalta, S., Sullivan, D., \& Markus, H. R. (2019). The psychology of neoliberalism and the neoliberalism of psychology. Journal of Social Issues, 75(1), 189-216. https://doi.org/10.1111/josi.12305

Barlow, D. H. (2000). Unraveling the mysteries of anxiety and its disorders from the perspective of emotion theory. American Psychologist, 55(11), 1247-1263. https://doi.org/10.1037//0003-066x.55.11.1247

Bauman, Z. (2017). Akışkan modernite (S. O. Çavuş, Çev). İstanbul: Can Yayınları.

Brijnath, B. \& Antoniades, J. (2016). "I'm running my depression:” Self-management of depression in neoliberal Australia. Social Science and Medicine, 152, 1-8. https://doi.org/10.1016/j.socscimed.2016.01.022

Cabanas, E. (2016). Rekindling individualism, consuming emotions: Constructing "psytizens" in the age of happiness. Culture \& Psychology, 22(3), 467-480. https://doi.org/10.1177/1354067X16655459

Calder-Dawe, O. \& Gavey, N. (2019). Feminism, Foucault, and Freire: A dynamic approach to sociocultural research. Qualitative Psychology, 6(3), 216-231. https://doi.org/10.1037/qup0000106

Carr, S. \& Batlle, I. C. (2015). Attachment theory, neoliberalism, and social conscience. Journal of Theoretical and Philosophical Psychology, 35(3), 160-176. https://doi.org/10.1037/a0038681

Cole, E. R. (2009). Intersectionality and research in psychology. American Psychologist, 64(3), 170-180. https://doi.org/10.1037/a0014564

Cosgrove, L. \& Vaswani, A. (2020). Fetal rights, the policing of pregnancy, and meanings of the maternal in an age of neoliberalism. Journal of Theoretical and Philosophical Psychology, 40(1), 43-53. https://doi.org/10.1037/teo0000139

Curran, T. \& Hill, A. P. (2019). Perfectionism is increasing over time: A meta-analysis of birth cohort differences from 1989 to 2016. Psychological Bulletin, 145(4), 410-429. http://dx.doi.org/10.1037/bul0000138

Cushman, P. (1990). Why the self is empty: Toward a historically situated psychology. The American Psychologist, 45(5), 599-611. https://doi.org/10.1037/0003-066X.45.5.599

De La Fabián, R. \& Stecher, A. (2018). Positive psychology and the enhancement of happiness: A reply to Binkley (2018). Theory \& Psychology, 28(3), 411-417. https://doi.org/10.1177/0959354318772098

Duff, J., Rubenstein, C., \& Prilleltensky, I. (2016). Wellness and fairness: Two core values for humanistic psychology. Humanistic Psychologist, 44(2), 127-141. https://doi.org/10.1037/hum0000020

Foucault, M. I. (2015). İktidarın gözü (I. Ergüden, Çev). İstanbul: Ayrıntı Yayınları.

Georges, C. M. \& Tomlinson-Clarke, S. M. (2015). Integrating positive psychology into counseling psychology $\begin{array}{lllll}\text { doctoral } & \text { education. The } & \text { Counseling } & \text { Psychologist, } & \text { 43(5), }\end{array}$ https://doi.org/10.1177/0011000015584067

Held, B. S. (2002). The tyranny of the positive attitude in America: Observation and speculation. Journal of Clinical Psychology, 58(9), 965-991. https://doi.org/10.1002/jclp.10093

Herrawi, F., Logan, J., Cheng, C.-P., \& Cosgrove, L. (2021). Global health, human rights, and neoliberalism: The need for structural frameworks when addressing mental health disparities. Journal of Theoretical and Philosophical Psychology. Advance online publication. https://doi.org/10.1037/teo0000192

Kagitcibasi, C. (2013). Adolescent autonomy-relatedness and the family in cultural context: What is optimal? Journal of Research on Adolescence, 23(2), 223-235. https://doi.org/10.1111/jora.12041

LaMarre, A., Smoliak, O., Cool, C., Kinavey, H., \& Hardt, L. (2019). The normal, improving, and productive self: Unpacking neoliberal governmentality in therapeutic interactions. Journal of Constructivist Psychology, 32(3), 236-253. https://doi.org/10.1080/10720537.2018.1477080 
Magyar-Moe, J. L., Owens, R. L., \& Scheel, M. J. (2015). Applications of positive psychology in counseling psychology: Current status and future directions. The Counseling Psychologist, 43(4), 494-507. https://doi.org/10.1177/0011000015581001

Martínez-Guzmán, A. \& Lara, A. (2019). Affective modulation in positive psychology's regime of happiness. Theory \& Psychology, 29(3), 336-357. https://doi.org/10.1177/0959354319845138

May, R. (1980). Psychology and the human dilemma W W Norton \& Co. APA PsycNet sitesinden alınmıştır: https://psycnet.apa.org/record/1996-97848-000

McAdams, D. P. (1996). Personality, modernity, and the storied self: A contemporary framework for studying persons. Psychological Inquiry, 7(4), 295-321. https://doi.org/10.1207/s15327965pli0704_1

Miller, A. (2008). A Critique of positive psychology or the new science of happiness. Journal of Philosophy of Education, 42(3-4), 591-608. https://doi.org/10.1111/j.1467-9752.2008.00646.x

Moradi, B. \& Grzanka, P. R. (2017). Using intersectionality responsibly: Toward critical epistemology, structural analysis, and social justice activism. Journal of Counseling Psychology, 64(5), 500-513. https://doi.org/10.1037/cou0000203

Neilson, D. (2015). Class, precarity, and anxiety under neoliberal global capitalism: From denial to resistance. Theory \& Psychology, 25(2), 184-201. https://doi.org/10.1177/0959354315580607

Prilleltensky, I. (2008). The role of power in wellness, oppression, and liberation: the promise of psychopolitical validity. Journal of Community Psychology, 36(2), 116-136. https://doi.org/10.1002/jcop.20225

Ratner, C. (2019). Neoliberal psychology. In Neoliberal Psychology (pp. 145-174). Springer.

Ratts, M. J. (2009). Social justice counseling: Toward the development of a fifth force among counseling paradigms. Journal of Humanistic Counseling, Education and Development, 48(2), 160-172. https://doi.org/10.1002/j.2161-1939.2009.tb00076.x

Rosenthal, L. (2016). Incorporating intersectionality into psychology: An opportunity to promote social justice and equity. American Psychologist, 71(6), 474-485. https://doi.org/10.1037/a0040323

Schwartz, B. (2000). Self-determination: The tyranny of freedom. American Psychologist, 55(1), 79-88. https://doi.org/10.1037/0003-066X.55.1.79

Silvia, P. J. \& O'Brien, M. E. (2004). Self-awareness and constructive functioning: Revisiting "the human dilemma". Journal of Social and Clinical Psychology, 23(4), 475-489. https://doi.org/10.1521/jscp.23.4.475.40307

Smith, L. (2008). Positioning classism within counseling psychology's social justice agenda. The Counseling Psychologist, 36(6), 895-924. https://doi.org/10.1177/0011000007309861

Steger, M. B., \& Roy, R. K. (2010). Neoliberalism: A very short introduction (Vol. 222). Oxford University Press.

Sugarman, J. (2015). Neoliberalism and psychological ethics. Journal of Theoretical and Philosophical Psychology, 35(2), 103-116. https://doi.org/10.1037/a0038960

Teo, T. (2017). From psychological science to the psychological humanities: Building a general theory of subjectivity. Review of General Psychology, 21(4), 281-291. https://doi.org/10.1037/gpr0000132

Vera, E. M. \& Shin, R. Q. (2006). Promoting strengths in a socially toxic world: Supporting resiliency with systemic interventions. The Counseling Psychologist, 34 34(1), https://doi.org/10.1177/0011000005282365 


\section{EXTENDED ABSTRACT}

In the course of neoliberalism; self, emotions, power relations were restructured in line with both micro and macro governmentality practices. In this review, the penetration of neoliberal policies to psychology and more specifically to counseling are critically discussed. When the literature is examined, the themes of the neoliberal subject as micro governmentality object, the internalized discipline as the form of micro governmentality, the marketization of psychology, and new forms of individuality as well as selfhood through various practices were stressed.

There are three basic discourses of the neoliberal self: the normal, productive, and developing self (LaMarre Smoliak, Cool, Kinavey, \& Hardt, 2019). The basic philosophy of these discourses is that the self is its own entrepreneur and developer as the project results of a process of micro governmentality and internal discipline. These practices obscure the neoliberal power relations and make them difficult to transform. In line with this reasoning, the individual perceives the cause of systemic problems as the inability to sufficiently develop themselves as an investment object or as a failure to effectively use selfregulation strategies.

One of the important phenomena in the relationship between neoliberal discourse and self is uncertainty. The basic philosophy of the prominence of uncertainty is to blur the causes of systemic inequalities by placing excessive emphasis on personal autonomy (Calder-Dawe \& Gavey, 2019). Besides self and personal autonomy, another phenomenon implicitly manipulated in the neoliberal system is the emotions like anxiety, guilt, and happiness.

Work-related uncertainty may boost ontological anxiety. Hence, individuals may experience intertwined anxiety of missing unlimited opportunities and losing their work. The acquisition of skills such as risk-taking and self-regulation to cope with this anxiety turns into pressure on the individual. This pressure may transform ontological anxiety into a feeling of guilt. At the same time, in the neoliberal system, the individual has to be overwhelmed in the happiness ocean by dealing with negative emotions like anxiety. In this context, happiness functions as a currency to facilitate internalizing neoliberal disciplines (De La Fabián \& Stecher, 2018). This happiness industry, which has existed since the end of the twentieth century, is depicted by the analogy of the tyranny of positivity (Held, 2002).

All in all, expecting the self to construct its own story by using unlimited possibilities in the age of positivity can turn into a kind of neoliberal oppression. Based on these premises, the neoliberal domination of self should also be taken into account in the field of counseling. In the face of intertwined structural pressures, the liberating function of the counseling relations is also important in the implicit disciplinary processes internalized by the individual. Therefore, the necessity to integrate social justice as the guiding paradigm in counseling after psychoanalytic, cognitive-behavioral, humanistic/existentialist and multicultural trend is discussed (Ratts, 2009). In that vein, the proposition that wellness and fairness are the basic values for the humanist model (Duff, Rubenstein \& Prilleltensky, 2016) is also valid for counseling relations. In this neoliberal age, the development of phenomena such as happiness, flow, mindfulness, and self-management in clients only makes sense when integrated with social justice-based perspective as well as intersectionality paradigm. 